\title{
PATRIMÔNIO CULTURAL E EDUCAÇÃO PATRIMONIAL: A OPERAÇÃO HISTORIOGRÁFICA E A TÁTICA MARGINAL
}

\author{
João Lorandi Demarchi \\ Universidade de São Paulo \\ joao.1.demarchi@gmail.com
}

Simone Scifoni Universidade de São Paulo simone.scifoni@gmail.com

\begin{abstract}
RESUMO
Para refletir sobre as relações entre o campo do patrimônio cultural e da educação patrimonial, recorreu-se à fundamentação teórica desenvolvida por Michel de Certeau. A partir deste autor, o patrimônio cultural é observado como um modo de se escrever a história pelos órgãos de preservação num dado momento específico. Já a educação patrimonial pode se configurar em práticas ordinárias que, como táticas, possibilitam a emersão das memórias recalcadas pela história materializada pelos bens patrimonializados, normalmente monumental e vinculada a fatos excepcionais. Ainda assim, há práticas de educação patrimonial alinhadas à estratégia do patrimônio consagrado e reificadoras da seleção abusiva operada pela história escrita por meio dos patrimônios. Para esse esforço reflexivo, este artigo analisa o Projeto Interação (1982-1985) e o Guia Básico de Educação Patrimonial (1999).
\end{abstract}

Palavras-chaves: Educação patrimonial. Escrita da história. Práticas ordinárias.

\section{CULTURAL HERITAGE AND PATRIMONIAL EDUCATION: THE HISTORIOGRAPHICAL OPERATION AND THE MARGINAL TACTIC}

\begin{abstract}
To reflect on the relationship between the field of cultural heritage and heritage education, this article resorted to the theoretical foundation developed by Michel de Certeau. From this author, cultural heritage is observed as a way of writing history by the preservation agencies at a specific moment. On the one hand, heritage education can be configured in ordinary practices that, as tactics, allow the emergence of memories repressed by the history materialized by patrimonial goods, usually monumental and linked to exceptional facts. On the other hand, there are practices of heritage education aligned with the consecrated heritage strategy and reifying the abusive selection operated by written history through heritage. For this reflective effort, this article also analyzes the Projeto Interação (1982-1985) and the Guia Básico de Educação Patrimonial (1999).
\end{abstract}

Keywords: Heritage education. History writing. Ordinary practices.

Rev. Iberoam. Patrim. Histórico-Educativo, Campinas (SP), v. 5, p. 1-17, e019029, 2019. 


\title{
PATRIMONIO CULTURAL Y EDUCACIÓN PATRIMONIAL: OPERACIÓN HISTORIOGRÁFICA Y TÁCTICA MARGINAL
}

\begin{abstract}
RESUMEN
Para reflexionar sobre la relación entre el campo del patrimonio cultural y la educación patrimonial, recurrimos a la base teórica desarrollada por Michel de Certeau. De este autor, las agencias de preservación observan el patrimonio cultural como una forma de escribir la historia en un momento específico. Por otro lado, la educación patrimonial puede configurarse en prácticas ordinarias que, como tácticas, permiten el surgimiento de recuerdos reprimidos por la historia materializada por bienes patrimoniales, generalmente monumentales y vinculados a hechos excepcionales. Por otro lado, hay prácticas de educación patrimonial alineadas con la estrategia consagrada del patrimonio y reificando la selección abusiva operada por la historia escrita a través del patrimonio. Para este esfuerzo reflexivo, este artículo también analiza el Projeto Interação (1982-1985) y la Guia Básico de Educação Patrimonial (1999).
\end{abstract}

Palabras claves: Educación patrimonial. Escritura de la historia. Prácticas ordinarias.

\section{PATRIMOINE CULTUREL ET EDUCATION PATRIMONIALE: L'OPERATION HISTORIOGRAPHIQUE ET LA TACTIQUE MARGINALE}

\section{RESUME}

Pour réfléchir aux relations entre le domaine du patrimoine culturel et l'éducation au patrimoine, nous avons eu recours aux bases théoriques développées par Michel de Certeau. De cet auteur, le patrimoine culturel est observé comme un moyen d'écrire l'histoire par les organes de préservation à un moment donné. D'autre part, l'éducation patrimoniale peut être configurée dans des pratiques ordinaires qui permettent, comme tactique, l'émergence de mémoires réprimées par l'histoire matérialisée par des biens patrimoniaux, généralement monumentaux et liés à des faits exceptionnels. D'autre part, il existe des pratiques d'éducation au patrimoine alignées sur la stratégie du patrimoine consacré et sur la réification d'une sélection abusive opérée par l'histoire écrite à travers le patrimoine. Pour cet effort réflexif, cet article analyse également le Projeto Interação (1982-1985) et le Guia Básico de Educação Patrimonial (1999).

Mots-clés: Education au patrimoine. Écriture de l'histoire. Pratiques ordinaires. 
A ficção do conhecimento está relacionada a essa luxúria de ser um ponto de vista e nada mais.

Michel de Certeau

\section{INTRODUÇÃO}

Fundado em 1937, sob a lei nº 378, o Serviço do Patrimônio Histórico e Artístico Nacional (Sphan), atual Instituto do Patrimônio Histórico e Artístico Nacional (Iphan), foi criado com "a finalidade de promover, em todo o País e de modo permanente, o tombamento, a conservação, o enriquecimento e o conhecimento do patrimônio histórico e artístico nacional" (BRASIL, 1937, art. 46). Assim, foi criado sob o governo de Getúlio Vargas um órgão que seria responsável por todo o processo de patrimonialização dos bens nacionais, que teria como missão desde identificar aquilo que seria considerado patrimônio cultural brasileiro, até se responsabilizar pela sua conservação e promoção.

Este presente artigo parte da percepção que, por meio deste órgão, o Estado brasileiro identifica aquilo que considera patrimônio cultural nacional para construir uma representação de si. Com os patrimônios nacionais há a escrita da história do Brasil. Para a análise crítica sobre este esforço do governo em construir uma narrativa do passado brasileiro, serão recorridos o pensamento de Michel de Certeau e os conceitos desenvolvidos por ele. Assim, é possível considerar que esta escrita da história, que se dá por meio do patrimônio cultural, está condicionada pela instituição e pelos sujeitos que atuam nela pois permitem que determinadas coisas sejam ditas, assim como impossibilita a enunciação de outras. Adota-se uma perspectiva próxima à da análise feita por Manoel Guimarães sobre a construção narrativa desenvolvida pelo Instituto Histórico e Geográfico Brasileiro (IHGB) que, seguindo as colocações de Michel de Certeau, considera que o lugar de onde o discurso historiográfico é produzido desempenha "um papel decisivo na construção de uma certa historiografia e das visões e interpretações que ela proporá na discussão da questão nacional" (GUIMARÃES, 1988, p. 5).

Dessa forma, é necessário olhar criticamente para o lugar social constituído pelo órgão de preservação do patrimônio cultural para perceber a atuação de determinados sujeitos que vão configurando a instituição e suas possíveis construções da história nacional.

A partir do olhar certeauniano, o artigo considera que a instituição de preservação pode funcionar como um poder central que, escrevendo a história do Brasil, monopoliza essa narrativa

Rev. Iberoam. Patrim. Histórico-Educativo, Campinas (SP), v. 5, p. 1-17, e019029, 2019. 
e intenta instaurar uma específica forma de compreender o passado. No entanto, esse esforço não é suficiente para determinar o significado e o sentido que terão os bens culturais para as pessoas nos seus cotidianos. Isso quer dizer que a prática ordinária da população dá golpes na determinação do governo federal, e cria táticas de sobrevivência, ressemantizando aquilo que foi eleito como patrimônio nacional. Esses golpes podem ser observados pelos diversos tipos de intervenções nos bens, tais como pichações - dos quais é possível ainda perceber variações: dizeres que manifestam posições ideológicas, expressões amorosas, marcações identitárias entre outras - ou ainda intervenções políticas como os índios que jogam tinta vermelha, representando sangue, no Monumento às Bandeiras, próximo ao Parque do Ibirapuera ${ }^{1}$, protestando contra aquele símbolo de civilização que também é símbolo de barbárie (BENJAMIN, 2016). Esse arcabouço teórico ajuda na compreensão dessas intervenções e nos leva a pensar nas potencialidades de tática da educação patrimonial (EP) como uma prática marginal, uma atuação de resistência frente às determinações da instituição governamental.

Este artigo trabalha com a hipótese de que a EP tem um lugar secundário dentro do órgão, como afirma Oliveira (2011, p. 29) "a educação patrimonial não tem sua importância totalmente reconhecida dentro do Iphan, pois ainda é vista por muitos como atividade acessória". A autora identifica ainda "que a educação patrimonial não constitui uma política pública, visto que não existem programas e ações suficientemente desenvolvidos e direcionados para esse fim" (OLIVEIRA, 2011, p. 6). Está, assim, a EP à margem da atuação principal do órgão de preservação. No entanto, esse problema pode ser visto sob a ótica otimista pois nessa posição é possível que por meio da ação educativa mediatizada pelo patrimônio cultural sejam estabelecidas táticas que subvertam a lógica central que determina uma específica narrativa histórica.

Nesse sentido, uma primeira potencialidade da EP é possibilitar a pluralidade de narrativas históricas sobre o Brasil. Se for dialógica, ela permite que outros sujeitos sociais pronunciem suas memórias. Consistirá em tratar a memória, conforme quis Simone Weil (BOSI, 2003, p. 16), como “um Direito Humano semelhante a outros direitos ligados à sobrevivência”. Possibilitará, também, por meio da EP que as "memórias subterrâneas" (POLLACK, 1989) que foram recalcadas pela história escrita pelo Estado retornem, emerjam. A representação dessa forma de atuação será demostrada na análise do Projeto Interação entre a Educação Básica e os Diferentes Contextos

\footnotetext{
${ }^{1}$ Ver: http://g1.globo.com/sao-paulo/noticia/2013/10/manifestantes-jogam-tinta-vermelha-no-monumentobandeiras.html
} 
Culturais Existentes no País ${ }^{2}$ que foi executado entre 1982 e 1985 e pelas práticas atuais da Coordenação de Educação Patrimonial (Ceduc), criada em 2004 como Gerência de Educação Patrimonial (Geduc). No entanto, se se detecta essas práticas que golpeiam a história escrita pela instituição, há também práticas de EP que contribuem para a história única contada pela instituição federal e, por isso, sejam fomentadas como a EP do órgão, esse é o caso do Guia Básico de Educação Patrimonial ${ }^{3}$ (HORTA, GRUMBERG, MONTEIRO; 1999) que foi publicado pela primeira vez em 1999, mas teve sua metodologia apresentada em 1983, no Museu Imperial.

A segunda potencialidade da EP sob a contribuição conceitual de Michel de Certeau é, sendo uma prática que permite a emersão das narrativas recalcadas, ela cria embasamentos teóricometodológicos para compreender as práticas cotidianas dos sujeitos ordinários. Supera aquela epistemologia sobre a qual ele se refere que está baseada em "categorias de saber rústicas e modos de análise por demais elaborados para permitir-nos imaginar a incrível abundância inventiva das práticas cotidianas" (CERTEAU; GIRAD; MAYOL; 2013, p. 342). Então o que se considera como patrimônio deixa de ser aquele racionalizado, monumental e excepcional para ser aquele portador de referências aos grupos e aos quais os sujeitos atribuem valor. A EP, nesse sentido, torna-se uma ciência que valoriza a cultura popular, sem idealizá-la, tampouco despolitizá-la.

Considerando o patrimônio cultural no seu contexto urbano, a EP pode ainda incentivar o olhar crítico para as relações urbanas. Se a condição de praticante da cidade, faz com que as pessoas vivam abaixo do limiar da visibilidade sobre essas relações (CERTEAU, 1994, p. 23), há sempre a possibilidade de torná-las um objeto de análise. Deve ser percebido, portanto, a despeito do "discurso utópico urbanístico" que tenta definir os usos, que, paradoxalmente, "a vida urbana permite cada vez mais a re-emergência do elemento que o projeto urbanístico excluía. A linguagem do poder é em si mesma 'urbanizante', mas a cidade torna-se presa dos movimentos contraditórios que contrabalançam e se combinam fora do alcance do poder panóptico" (CERTEAU, 1994, p. 26). Portanto, embora a "cidade-Conceito venha decaindo" é possível analisar a efervescência dessas práticas, "como micróbios, que se espera sejam administradas ou suprimidas por um sistema urbanístico, mas que sobreviveram à deterioração". Isso quer dizer que os sujeitos das cidades, os habitantes constroem uma segunda geografia poética, ressignificando o sentido pensado pelo poder

\footnotetext{
${ }^{2}$ A partir de agora: Projeto Interação.

${ }^{3}$ A partir de agora: Guia
} 
central, para além daquela geografia do sentido literal (CERTEAU, 1994, p. 31), e a análise crítica dessas relações pode ser ensejada pela EP.

\section{PATRIMÔNIO NACIONAL: UMA ESCRITA DA HISTÓRIA}

A eleição de determinados bens culturais definidos como patrimônios nacionais escreve uma determinada história do país. Essa história é escrita de um determinado lugar e por determinadas pessoas. Isso significa que a configuração dessa história escrita - no caso do patrimônio cultural, materializada - está condicionada às influências desses fatores. Enquanto a representação desse passado recria uma narrativa para atingir interesses específicos, ela recalca outras tantas possíveis. Mas o recalcado sempre retorna. Nessa seção será discutido como foi construída a história do Brasil por meio do patrimônio.

\section{Sujeitos na instituição: representação do passado}

A contribuição de Marcia Chuva $(2003 ; 2009)$ é paradigmática para a compreensão da história do Iphan. A abordagem dela se aproxima da perspectiva proposta por Michel de Certeau a respeito da escrita da história. A autora demonstra como a ideia de patrimônio histórico e artístico nacional nasce vinculada aos ideais varguistas de tentativa de unificar a nação. Nesse empreendimento a figura de determinados intelectuais foi fundamental. É o caso dos seguintes modernistas: Rodrigo Melo Franco de Andrade, Lucio Costa e Carlos Drummond de Andrade que vão perfilar o que é nacional e qual seu patrimônio a partir de uma óptica da universalidade da cultura e da arte. A escrita dessa história buscou vincular a identidade brasileira ao passado português. Foi, desse modo, no período estadonovista que se construiu a narrativa evolutiva que instaurou um tempo brasileiro, diferente do português, mas advindo dele. Houve, com isso, a "barroquização" do patrimônio e determinou a característica do patrimônio nacional.

Com Certeau, percebemos que a escrita da história está condicionada ao presente, há possibilidades de uma produção (CERTEAU, 2017, p. XXIV). A escrita da história revela muito mais sobre o presente que escreveu do que o passado que foi objeto de análise. Nesse sentido, em consonância com a perspectiva de Marcia Chuva, este artigo busca compreender as condições que 
permitiram uma específica construção de um passado glorioso, rico, vinculado à Europa, configurando um perfil homogêneo da identidade brasileira.

O Decreto-lei no 25/1937, no seu Artigo 1º declara: “Constitui o patrimônio histórico e artístico nacional o conjunto de bens móveis e imóveis existentes no país e cuja conservação seja de interesse público, quer por sua vinculação a fatos memoráveis da História do Brasil, quer por seu excepcional valor arqueológico ou etnográfico, bibliográfico ou artístico" (grifo nosso). Com a contextualização de Chuva fica claro o problema de origem da formação do patrimônio nacional brasileiro. A história escrita pelos modernistas por meio da materialidade do patrimônio será aquela de "excepcional valor" e vinculado a "fatos memoráveis". A contribuição da autora afina-se com o que Certeau percebe da operação da escrita da história: “O passado é, também, ficção do presente [...]. O real que se inscreve no discurso historiográfico provém das determinações de um lugar" (CERTEAU, 2017, p. XXIII). Portanto, a escrita da história nacional a partir do patrimônio nacional não é a descoberta de uma verdade escondida. "Ela constitui símbolo pela própria relação entre um espaço novo recortado no tempo e um modus operandi que fabrica 'cenários' suscetíveis de organizar práticas num discurso hoje inteligível - aquilo que é propriamente "fazer história"” (CERTEAU, 2017, p. XIX).

No entanto, o próprio Michel de Certeau problematiza essa operação historiográfica revelando as disputas de poder que se dão pela representação do passado, fundada em violências. É sempre a violência que funda um saber (CERTEAU, 2012b, p. 81). Para ele, "a relação científica reproduz o trabalho que assegura a certos grupos a dominação sobre os outros, a ponto de fazer deles objetos de sua posse" (CERTEAU, 2017, p. 28). A elite que escreve sua história e valoriza sua memória, alija das narrativas as culturas populares, desprezando o seu direito à memória. A escrita da história revela-se um campo de batalha.

Esse modo de se relacionar com a cultura popular em que se recalca suas manifestações, para Certeau, é estéril. Trata-se da "beleza do morto" que o autor conceitua. A construção de uma determinada identidade social é a diferenciação de uma época anterior ou de uma outra sociedade. Esse posicionamento se dá tanto pela negação ao que eu não quero me aproximar quanto pela afirmação daquilo com o que eu quero me identificar (CERTEAU, 2017, p 40). A representação do passado é a relação dialética entre a ausência e a presença do morto, ou seja, daquilo que passou. Se por um lado "a coisa comunicada opera a comunicação de um grupo consigo mesmo pelo 
remetimento ao terceiro ausente que é o seu passado" (CERTEAU, 2017, p. 41); por outro lado essa coisa não pode se posicionar a favor ou contra o que lhe é feito.

No caso da origem do patrimônio nacional, na década de 1930, fica evidente a não inocência dos procedimentos do fazer história. Há uma intencionalidade que está condicionada pelo seu presente. Os modernistas construíram uma história do Brasil por meio do patrimônio cultural que buscava instaurar uma identidade nacional, se aproximando do que Benedict Anderson (2008) chamou de "comunidades imaginadas", isto é, o patrimônio contribuindo para a comunhão entre os cidadãos de um território, forjando o sentimento nacional. Conquanto esse poder central busca determinar um sentido e um significado para os diversos bens patrimonializados, nas práticas cotidianas dos sujeitos ordinários isso pode ser ressemantizado. Há consumos ativos que implicam em ressignificações. A violência que funda o saber da produção historiográfica, conforme indica Certeau, não é suficiente para perfilar os infinitos modos de apropriação. Essas são as táticas com que os fracos, para tirar vantagem do forte, produzem seus próprios significantes (CERTEAU, 1998, p. 45).

\section{Não se determina o sentido: retorno do recalcado}

Leitor de Freud, Certeau indica que o recalcado também na escrita da história retorna. A "seleção abusiva" dos elementos do passado, que são mobilizados para se inteligir no presente essa narrativa, instaura uma cultura singular e uma história única. Dessa forma, aludindo ao ensino do francês discutido por Certeau (2012b), o patrimônio cultural, tal como é concebido pelos modernistas e definido pelo Decreto-lei $n^{\circ}$ 25/37, obstaculiza a iniciação cultural às diferenças, estando avessa à diversidade e pluralidade das narrativas nacionais.

Por outro lado, a Constituição de 1988 no artigo 216 define: "constituem patrimônio cultural brasileiro os bens de natureza material e imaterial, tomados individualmente ou em conjunto, portadores de referência à identidade, à ação e à memória dos diferentes grupos formadores da sociedade brasileira" (grifo nosso). Há um importante avanço conceitual, como demonstra Meneses (2012), em que se desloca a matriz, agora, reconhecendo que o patrimônio é uma atribuição de valor dos grupos que formam a sociedade brasileira. Supera-se nessa nova Carta aquele patrimônio monumental e excepcional de 1937, uma vez que importam os bens portadores 
de "referência à identidade, à ação e à memória dos diversos grupos", leva-se em consideração a cultura no plural.

Como afirma um dos Princípios da Rede Paulista de Educação Patrimonial - Repep ${ }^{4}$ (2014): "se o patrimônio cultural se configura como campo de disputa de significados, qualquer ação que ocorra a seu respeito deve se nutrir pelo respeito à diversidade de possibilidades de construção de narrativas, interpretações e sentidos sobre o patrimônio".

Mesmo com essas significativas transformações que se dão por diferentes frentes, pelo texto constitucional e pela pressão da sociedade civil, o problema da escrita da história não se resolve apenas ao possibilitar as múltiplas narrativas. Por se tratar de um problema de ordem política, pois possui uma função social, questiona-se Certeau (2012b, p. 80): “de onde se fala, o que se pode dizer? Mas também, enfim: de onde falamos nós?”. É necessário, primeiro, o entendimento de onde se fala e, segundo, a enunciação desse ponto de vista. Nesse trecho citado, Certeau discute sobre o poder repressivo da cultura erudita, mas considera que toda escrita da história seleciona e descarta, independente da classe social. Em toda escrita da história "nada se oferece, tudo deve ser tomado, e a mesma violência da interpretação pode aqui criar ou suprimir" (CERTEAU, 2012b, p. 80). A saída tampouco é somar as narrativas. A solução é algo que se aproxima da proposta de Hannah Arendt sobre o espaço público ser o âmbito da discussão, portanto da diferença. A proposta de Michel de Certeau (2012b, p. 79) é defender que se deve "fazer com que apareçam suas leis, ouvir seus silêncios", ou seja, explicitar de onde se fala.

Dessa forma, qualquer patrimônio cultural que expresse a construção de uma identidade, justificando sua existência na história e no espaço, recalca outras narrativas. Está claro que a elite pela sua força política exerce esse seu poder de modo mais contundente e recorrente a justificar e legitimar a permanência de sua posição de dominação. Mas sempre há a possibilidade do retorno do recalcado.

Considerando que na sociedade capitalista o Estado representa os interesses dos setores hegemônicos, a despeito da democratização delineada no Artigo 216 que concede ao Estado o reconhecimento do patrimônio cultural pleiteado pela sociedade. É, em última instância, a classe dominante que reconhecerá ou não, a depender dos seus interesses, a salvaguarda dos bens culturais

\footnotetext{
${ }^{4}$ Coletivo educador, criado em 2012 a partir de um projeto de cultura e extensão da Universidade de São Paulo, formado por pessoas que se voluntariam a discutir educação patrimonial e propor atuações junto à sociedade civil.
} 
apresentados. No entanto, a luta pelo direito à emersão do recalcado é possível pressionando pela utilização do texto constitucional ou pelas vias alternativas ao instituído. Por isso, conforme Ana Carmen Casco (2014), a sociedade civil promove ações educativas em torno daqueles bens culturais que ela considera seus patrimônios para ocupar um vazio deixado pelo Estado.

\section{EDUCAÇÃO PATRIMONIAL: UMA ESTRATÉGIA MARGINAL}

Diante do panorama apresentado, a EP é, portanto, o lugar da possibilidade de se golpear o enquadramento da história escrita pelo poder central, representado aqui na figura do Iphan. Por ela estar à margem das políticas públicas e ser considerada um acessório nas políticas de preservação do patrimônio cultural, isso permite que ela seja tática para a emersão das identidades e culturas recalcadas. Enquanto a escrita da história pelo Iphan se configuraria no âmbito da estratégia, que segundo Certeau (1998), é o espaço do sujeito de poder; a EP está no campo da tática, são aquelas ações ordinárias, dos sujeitos que estão dentro do campo do inimigo.

A abordagem do patrimônio cultural realizada pelo Iphan opera com o mito da unidade original, que além de idealizar a cultura popular, dicotomiza a população e o Estado. Esse empreendimento se aproxima da produção de incompetentes, conceito elaborado por Marilena Chaui. Não são todos que podem dizer tudo a qualquer momento. São só os especialistas, que dominam o saber técnico-científico, que terão a legitimidade de dizer o que deve ser feito ou não. Assim como Certeau (2012b, p. 124), referindo-se à escola francesa, observou que os professores são tratados como guardiães da "unidade original" que está associada à uma "pureza da língua"; os técnicos dos órgãos de preservação são os únicos conhecedores da história nacional e, portanto, só eles podem determinar o que é patrimônio cultural nacional. Isso implica na rejeição da diferença. Essa idealização do passado e da cultura popular é mais fácil e mais eficiente se efetuada sob a forma de monólogo (CERTEAU, 2012b, p. 59).

Portanto, a escrita da história por meio do patrimônio cultural mostra sua violência quando, hierarquizando as culturas, neutraliza a cultura ordinária. Ela torna-se um objeto de interesse porque seu perigo foi eliminado (CERTEAU, 2012, p. 55). Certeau, a partir de ter identificado esses problemas da escrita da história - que se aproximam, em alguma medida, dos abusos da memória (TODOROV, 1995, p. 16), em que um dos maus usos é tentar controlar o que será lembrado -, propõe a superação da hierarquia entre as culturas a fim de se atingir a "democracia

Rev. Iberoam. Patrim. Histórico-Educativo, Campinas (SP), v. 5, p. 1-17, e019029, 2019. 
cultural" (CERTEAU, 2012b, p. 81). Para este objetivo é que Certeau buscará construir uma nova epistemologia que seja capaz de compreender as riquezas das práticas cotidianas, valorizando-as. Ele propõe esse novo modo de pensar e olhar a realidade a partir da crítica tecida às bases teóricas das ciências humanas. Na sua perspectiva, elas impedem conhecer os "tipos de operações em jogo nas práticas ordinárias, seus registros e suas combinações”, pois preocupam-se com outros objetos e possuem outros objetivos (CERTEAU, GIARD, MAYOL; 2013, p. 341). Dessa forma, consumindo ativamente a discussão que ele faz sobre as escolas francesas, este artigo propõe que se mudarmos o conteúdo dos nossos patrimônios culturais poderemos questionar a organização da cultura (CERTEAU, 2012b, p. 123) indo ao encontro da proposta certeauniana de democratização da cultura.

\section{Projeto Interação}

O Projeto Interação foi uma linha programática planejada entre diversas secretarias em 1981 sob a construção das "Diretrizes para operacionalização da política cultural do MEC". Ele foi executado sob a ditadura civil-militar brasileira (1964-1985) entre 1982 e 1985 . No documento que define sua atuação está determinado o seguinte:

O objetivo fundamental é o desenvolvimento cultural, concebido como uma das dimensões essenciais para a ampla democratização da vida brasileira e voltado essencialmente para os setores menos favorecidos da população, numa perspectiva anti-elitista, comprometido com o conhecimento, a preservação e a dinamização dos valores culturais básicos do povo. (BRANDÃO et al., 1996, p. 301, grifos nossos).

Desse modo, destacam-se duas características. A primeira diz respeito à preocupação com a democratização em plena ditatura. Isso está relacionado à distensão que se iniciou no fim da década de 1970, no governo Geisel, em que houve o esforço de demonstrar comprometimento com a democratização da sociedade (FERREIRA, 2015). E há uma mudança na política cultural que incidirá sobre o patrimônio cultural que é a desvinculação daquele patrimônio monumental do

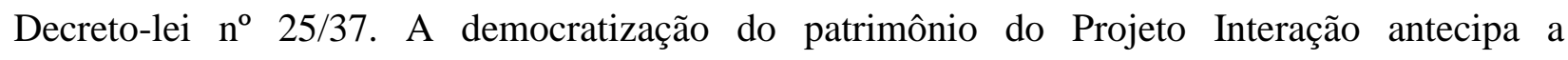
democratização da cultura presente no Artigo 216 na Constituição de 1988. A segunda característica refere-se às implicações dessa mudança do conteúdo, não mais tratar do patrimônio 
monumental, mas sim das referências culturais. Essa virada de ponto de vista muda o modo que a escola irá trabalhar e como ela abordará a cultura.

Uma vez que este projeto incentivou as escolas a trabalharem com as manifestações culturais do seu território, isso permitiu que elas passassem a valorizar as dinâmicas culturais cotidianas. Assim, há duas subversões neste âmbito. Primeiro subverte-se as avaliações externas que enquadram os conteúdos a serem abordados nas escolas e que acabam sendo mecanismos de controle. E subverte-se a lógica racionalista que valoriza apenas conteúdos propedêuticos. Por meio do Projeto Interação é lançado um novo olhar sobre a cultura em que a escola está inserida e tenta dar conta da riqueza das práticas ordinárias que relevam um caráter estético, na medida em que se trata de uma arte de fazer; de um caráter ético, pois os sujeitos recusam a ordem imposta, ressignificação no cotidiano; e de um caráter polêmico, que revela as táticas desses atores ordinários de se colocar no campo de forças em que eles são mais fracos.

O Projeto Interação, nessa perspectiva, instaura um novo modo de articular a escola básica com a cultura do seu entorno que tem implicações no fortalecimento da identidade dos alunos acarretando na elevação de sua autoestima e na conscientização de que eles são sujeitos históricos. O tratamento que o projeto dá à cultura vai ao encontro da saída encontrada por Certeau a partir da crítica elaborada por ele sobre as ciências humanas em relação à idealização da cultura popular, que é de neutralização. Consonante às ideias de Certeau, o Projeto Interação considerou que: "valorizar não significa tornar uma cultura melhor enquanto produto, mas fazê-la mais transparente enquanto processo" (BRANDÃO et al., 1996, p. 41).

A política de EP atual adotada pela CEDUC tem no Projeto Interação uma grande referência. As últimas publicações do Iphan $^{5}$ e a Portaria $n^{\circ}$ 137/2016 lançam bases para práticas educativas mediatizadas pelo patrimônio cultural que subvertem o conteúdo, logo repensam a cultura. A proposta metodológica dos Inventários Participativos das Referências Culturais trata de legitimar as referências culturais dos sujeitos ordinários. E nesse movimento, os valores afetivos são considerados assim como os valores racionalistas. Essa é uma boa saída para superar as categorias e instrumentos de análise que não conseguem perceber como a cultura do cotidiano é admirável.

\footnotetext{
${ }^{5}$ São elas: Iphan $(2014 ; 2016)$.
} 


\section{Guia Básico de Educação Patrimonial}

Embora a EP possa estar no campo da tática, trabalhar para a emersão das histórias e memórias recalcadas, contraposta às grandes narrativas, ela também pode reproduzir a história escrita pelos grandes monumentos, vinculando-se aos fatos memoráveis do Decreto-lei no 25/37. Este é o caso do Guia Básico de Educação Patrimonial (HORTA; GRUMBERG; MONTEIRO; 1999).

O Guia foi publicado em 1999, mas a metodologia veiculada nele fora apresentada em 1983, no $1^{o}$ Seminário sobre o Uso Educativo de Museus e Monumentos, realizado no Museu Imperial, em Petropólis-RJ. Como essas primárias informações já permitem relevar, este método de EP estava vinculado a monumentos e nasceu sob a escrita da história promovida pelo Museu Imperial. Como discutido à luz de Certeau, as (im)possibilidades das práticas historiográficas estão circunscritas aos lugares de onde se fala. A tradução do termo inglês heritage education empreendida pela diretora do Museu Imperial Maria de Lourdes Horta, a partir da sua experiência na Inglaterra, formalizou as práticas educativas com o patrimônio em quatro etapas: observação, registro, exploração e apropriação. Nelas, se busca aproximar os alunos dos patrimônios/monumentos a partir da apresentação material. Após, eles são convidados a registrarem o que viram, indicando aquilo que consideram relevante. Com isso, eles são instigados a pesquisarem mais sobre o objeto em questão. Por fim, espera-se a apropriação de cada aluno do patrimônio estudado.

Com este método, conforme expresso nas primeiras páginas do Guia, o objetivo é a “alfabetização cultural”. Embora a alfabetização seja definida pela cartilha como algo que "possibilita ao indivíduo fazer a leitura do mundo que o rodeia, levando-o à compreensão do universo sociocultural e da trajetória histórico-temporal em que está inserido" (HORTA; GRUMBERG; MONTEIRO; 1999, p. 5), buscando uma aproximação da conscientização proposta por Paulo Freire; ao se analisar criticamente o Guia depara-se com a contrariedade da alfabetização cultural.

A análise crítica mostra que, ao seguir as quatro etapas (Tabela 01), espera-se que os sujeitos preservem aqueles monumentos escolhidos de antemão pelos professores e que estão vinculados às grandes narrativas, muitas vezes tutelados pelos órgãos de preservação ou 
pertencentes aos acervos de museus. Mais do que a preservação física dos bens patrimoniais, objetiva-se a preservação do significado deles. Logo, ao reproduzir a história escrita pelos órgãos de preservação não se permite a emersão daquelas memórias e histórias subterradas. Como consequência, ao privilegiar o patrimônio material tutelado pelos órgãos de preservação, não se busca valorizar a cultura ordinária. Não são criados métodos que possibilitem a valorização da pluralidade de culturas. Desse modo, a "seleção abusiva" promovida pelo tombamento de determinados bens, vinculado à história monumental, é reiterada pela educação apresentada pelo Guia.

Tabela 01- As quatro etapas da metodologia de EP apresentada pelo Guia.

\begin{tabular}{|c|c|c|}
\hline Etapas & Recursos/Atividades & Objetivos \\
\hline 1) Observação & $\begin{array}{l}\text { exercícios de percepção } \\
\text { visual/sensorial, por meio de } \\
\text { perguntas, manipulação, } \\
\text { experimentação, medição, } \\
\text { anotações, comparação, dedução, } \\
\text { jogos de detetive... }\end{array}$ & $\begin{array}{l}\text { > identificação do } \\
\text { objeto/função/significado; } \\
\text { > desenvolvimento da perceção } \\
\text { visual e simbólica }\end{array}$ \\
\hline 2) Registro & $\begin{array}{l}\text { desenhos, descrição verbal ou } \\
\text { escrita, gráficos, fotografias, } \\
\text { maquetes, mapas e plantas baixas. }\end{array}$ & $\begin{array}{l}\text { > fixação do conhecimento } \\
\text { percebido, aprofundamento da } \\
\text { observação e análise crítica; } \\
\text { > desenvolvimento da memória, } \\
\text { pensamento lógico, intuitivo e } \\
\text { operacional. }\end{array}$ \\
\hline 3) Exploração & $\begin{array}{l}\text { análise do problema, levantamento } \\
\text { de hipóteses, discussão, } \\
\text { questionamento, avaliação, } \\
\text { pesquisa em outras fontes como } \\
\text { bibliotecas, arquivos, cartórios, } \\
\text { instituições, jornais, entrevistas. }\end{array}$ & $\begin{array}{l}\text { > desenvolvimento das capacidades } \\
\text { de análise e julgamento crítico, } \\
\text { interpretação das evidências e } \\
\text { significados. }\end{array}$ \\
\hline 4) Apropriação & $\begin{array}{l}\text { recriação, releitura, dramatização, } \\
\text { interpretação em diferentes meios } \\
\text { de expressão como pintura, } \\
\text { escultura, drama, dança, música, } \\
\text { poesia, texto, filme e vídeo. }\end{array}$ & $\begin{array}{l}\text { > envolvimento afetivo, } \\
\text { internalização, desenvolvimento da } \\
\text { capacidade de auto-expressão, } \\
\text { apropriação, participação criativa, } \\
\text { valorização do bem cultural. }\end{array}$ \\
\hline
\end{tabular}

Fonte: Horta, Grumberg e Monteiro (1999, p. 11).

Rev. Iberoam. Patrim. Histórico-Educativo, Campinas (SP), v. 5, p. 1-17, e019029, 2019. 


\section{CONCLUSÃO}

Ao estudar o problema do ensino da língua francesa, Certeau observou que nesta prática pedagógica são descartadas a pluralidade das apropriações linguísticas. A partir disso, ele reflete sobre a relação entre pesquisa e ensino, percebendo que se privilegia a difusão, em detrimento da pesquisa. Situação análoga a EP brasileira.

Nas grandes instituições, o que predomina é uma política centrada na satisfação imediata das necessidades e na organização administrativa. Administra-se e regase segunda a urgência. Em suma, faz-se pedagogia ou vulgarização. A pesquisa encontra-se indefinida. Contudo, na base, nas pequenas unidades, existe um fervilhar de pesquisas: pequenos laboratórios, experiências novas transformam tanto a disciplina quanto a relação pedagógica. (CERTEAU, 2012, p. 136).

Utilizando o pensamento certeauniano no campo da EP, este artigo buscou discutir como as práticas educativas relegadas à marginalidade permitem que novas experiências sejam desenvolvidas, transformando tanto o conteúdo do patrimônio quanto das relações pedagógicas. $\mathrm{O}$ órgão de preservação do patrimônio ao focar na vulgarização e na administração dos bens acautelados, desconsidera a pesquisa que permitiria a valorização da cultura no plural. Cabe, assim, a essas práticas marginais a responsabilidade pela emersão das memórias subterradas.

As instituições de proteção do patrimônio escrevem uma história por meio da escolha daqueles bens que deverão ou não ser registrados e tombados. Essa "seleção abusiva" configurase numa espécie de violência, uma vez que oblitera da narrativa diversos grupos sociais. Dessa forma, o pensamento de Michel de Certeau contribui para a reflexão crítica sobre as práticas educativas no campo patrimonial pois embasa uma nova epistemologia que repolitiza o campo da EP e convida a uma abordagem democrática da cultura.

\section{REFERÊNCIAS}

ANDERSON, Benedict. Comunidades Imaginadas. Trad. Denise Bottman. São Paulo: Companhia das Letras, 2008.

BENJAMIN, Walter. Sobre o conceito da História. In: O anjo da história. Organização e tradução de João Barrento. 2. ed. Belo Horizonte: Autêntica Editora, 2016. p. 07-20. 
BOSI, Ecléa. O tempo vivo da memória: ensaios de psicologia social. São Paulo: Ateliê Editorial, 2003.

BRANDÃO, Carlos Rodrigues et. al. O difícil espelho: limites e possibilidades de uma experiência de cultura e educação. Rio de Janeiro: Iphan/Depron, 1996.

BRASIL. Constituição (1937). Constituição da República Federativa do Brasil. Disponível em: https://www2.camara.leg.br/legin/fed/lei/1930-1939/lei-378-13-janeiro-1937-398059publicacaooriginal-1-pl.html . Acesso em: 17 out. 2019.

CARBÓ, Cristina, GIRAUD, François. Entrevista a Michel de Certeau. México, DF, Historicas, set./dic. 1982. p. 25-26 e 39-51.

CARBÓ, Cristina, GIRAUD, François. Entrevista a Michel de Certeau. México, DF, Historicas, enero/abril 1983. p. 19-20 e 41-53.

CASCO, Ana Carmen. Sociedade e Educação Patrimonial. Repep, 2014. Disponível em:. http://repep.fflch.usp.br/sites/repep.fflch.usp.br/files/SOCIEDADE\%20E\%20EDUCA\%C3\%87 \%C3\%830\%20PATRIMONIAL\%20CASCO_A.pdf . Acesso em : 23 jun. 2018.

CERTEAU, Michel de; GIARD, Luce; MAYOL, Pierre. A invenção do cotidiano: morar e cozinhar. 12. ed. Tradução: Ephraim F. Alves e Lúcia Endlich Orth. Petrópolis: Vozes, 2013.

CERTEAU, Michel de. Teoria e Método no Estudo no estudo das práticas cotidianas. In: SZMRECSANYI, Maria Ivone (Org.). Cotidiano, cultura popular e planejamento urbano (Anais do Encontro). São Paulo: FAU/USP, 1985. p. 3-19.

CERTEAU, Michel de. Andando na cidade. In: Revista do Patrimônio Histórico e Artístico Nacional, n. 23, 1994, p. 21-31. Disponível em http://portal.iphan.gov.br/uploads/publicacao/RevPat23_m.pdf . Acesso em: 21 jun. 2018.

CERTEAU, Michel de. A Invenção do cotidiano. Artes de fazer. 3. ed. Trad. Ephraim F. Alves. Petrópolis: Vozes, 1998.

CERTEAU, Michel de. História e psicanálise: entre ciência e ficção. 2 ed. Trad. Guilherme João de Freitas Teixeira. Belo Horizonte: Autêntica, 2012a. (Coleção História \& Historiografia, 3).

CERTEAU, Michel de. A Cultura no Plural. 7 ed. Trad. Enid Abreu Dobránzsky. Campinas, SP: Papirus, 2012b. (Coleção Travessia do Século)

CERTEAU, Michel de. A Escrita da história. 3 ed. Trad. de Maria de L. Menezes; rev. técnica [de] Arno Vogel. Rio de Janeiro: Forense Universitária, 2017.

CHUVA, Marcia R. R. Os Arquitetos da Memória: sociogênese das práticas de preservação do patrimônio cultural no Brasil (anos 1930-1940). Rio de Janeiro: Editora UFRJ, 2009. 
CHUVA, Marcia R. R.. "Fundando a nação: a representação de um Brasil barroco, moderno e civilizado". In: Topoi, v. 4, n. 7, p. 313-333, jul./dez. 2003.

FERREIRA, Luiza C. A. E a cultura ? O Centro Nacional de Referência Cultural e a identidade do Brasil (1975-1979). 2015. 131f. Dissertação (Mestrado) - Universidade Federal Fluminense. Niterói, RJ.

GUIMARÃES, Manoel Luiz Salgado. Nação e civilização nos trópicos: o Instituto Histórico e Geográfico Brasileiro e o projeto de uma História nacional. Estudos Históricos, 1, p. 5-27, 1988.

HORTA, Maria de Lourdes P.; GRUMBERG, Evelina; MONTEIRO, Adriane Q. Guia Básico de Educação Patrimonial. Brasília: Iphan, Museu Imperial, 1999.

INSTITUTO DO PATRIMÔNIO HISTÓRICO E ARTÍSTICO NACIONAL. Educação Patrimonial: inventários participativos: manual de aplicação. Texto Sônia Regina Rampim Florêncio et al. Brasília, DF, 2016.

INSTITUTO DO PATRIMÔNIO HISTÓRICO E ARTÍSTICO NACIONAL. Educação patrimonial: histórico, conceitos e processos. Texto Sônia Regina Rampim Florêncio e Rodrigo Ramassote. Brasília, DF: Iphan/DAF/Cogedip/Ceduc, 2014.

MENESES, Ulpiano. O campo do patrimônio cultural: uma revisão de premissas. In: I Fórum Nacional do Patrimônio Cultural: Sistema Nacional de Patrimônio Cultural: desafios, estratégias e experiências para uma nova gestão, 2009, Ouro Preto/MG. Anais [...] Brasília-DF: Iphan, vol. 1, 2012. p. 25-39.

MORAES, José Geraldo V.; GAMBETA, Wilson. Michel de Certeau: pensador das diferenças. In: REGO, Teresa. (Org.). Memória, história e escolarização. Petrópolis: Vozes, 2011, p. 157182. (Coleção Pedagógica Contemporânea, v. 3).

OLIVERIA, Cléo Alves P. Educação patrimonial no Iphan. 2011. 141f. Monografia (Especialização) - Escola Nacional de Administração Pública, Brasília, DF.

POLLAK, Michael. Memória, esquecimento, silêncio. Estudos Históricos, Rio de Janeiro, vol. 2, n. 3, p. 3-151989.

REPEP. Princípios da Educação Patrimonial. São Paulo: 2014. Disponível em: http://repep.fflch.usp.br/sites/repep.fflch.usp.br/files/u63/Principios\%20da\%20Repep.pdf. Acesso em: 18 abr. 2018.

TODOROV, Tzvetan. Los abusos de la memoria. Espanha: Ariea, 1995. 